\section{AS PROFESSORAS PRIMÁRIAS \\ dA Guanabara de LACERDA: \\ A CONSTRUÇÁO DO TIPO ANTROPOLÓGICO}

\author{
Maria Angélica da Gama Cabral Coutinho
}

Neste artigo, analisa-se a representação das professoras primárias do Estado da Guanabara, adotando como referência a análise do que Cornelius Castoriadis denominou de "o tipo antropológico", durante o primeiro governo de Lacerda. Discute-se, ainda, como essas professoras foram profundamente marcadas por essa gestáo.

Palavras-chave: Educação. Guanabara. Professora primária. Tipo antropológico.
Mestra em Educação - UERJ

Professora - Universidade Cândido Mendes e Universidade

Estácio de Sá e da Rede oficial do Estado do Rio de Janeiro.

Rio de Janeiro - RJ [Brasil]

mariangelicacoutinho@ig.com.br 


\section{Introdução}

Em I960, Brasília tornou-se a capital federal da República do Brasil. Este fato assumiu uma grande importância para a cidade do Rio de Janeiro, posto que, nesse momento, estruturava-se a Guanabara - a nova unidade da federação. $\mathrm{O}$ acontecimento exigiu a organização da primeira eleição para governador. A disputa eleitoral é bastante acirrada, envolvendo a população carioca e, ao final, garantindo a Carlos Lacerda o cargo de primeiro mandatário do pequeno estado recém-criado.

Lacerda, além da preocupação particular quanto à demarcação da identidade da nova unidade da federação, fixou-se em três pilares que serviram de mote de campanha: ampliação e distribuição da rede de abastecimento de água, reordenamento do espaço urbano do novo estado e ampliação das vagas na escola pública. Entre os três pontos, a educação assume relevante importância.

As professoras primárias da rede pública, nos anos 60 do século $\mathrm{XX}$, foram marcadas por grandes e polêmicas iniciativas adotadas pelo Governo do Estado da Guanabara concernentes à educação oficial. O resultado é que, apesar da enorme ambigüidade que sempre presidiu a política de valorização da educação pública de Carlos Lacerda - o governador da época em foco -, sua gestão é constantemente lembrada pelas professoras desse período como época áurea. Isso, de certa maneira, responde a uma grande parte da interrogação que levou à elaboração deste trabalho.

Em razão de ter, como uma de suas marcas, o paradoxo, busca-se, por meio deste estudo, reconstruir as diferentes facetas e iniciativas que caracterizaram a política educacional de Lacerda. Inicialmente, parece que a contradiçáo que, a distância, salta aos olhos - o fato de um defensor de o ensino privado ser, ao mesmo tempo, uma figura ímpar na memória da escola pública carioca - desfaz-se diante da certeza de que a ousadia de suas açóes e o resul- 
tado prático de suas realizaçóes, de fato, concorreram para colocar a educação na proeminência dos assuntos públicos.

Não se trata, portanto, do tipo e da natureza da política educacional de Lacerda, mas de seu objeto preferencial - eis como, sobretudo, Lacerda valorizou a educação. Mas, isso posto, de que forma afetou a instituição da escola pública da Guanabara? Quem eram as professoras que, ao mesmo tempo, instituíram a memória do período e por ele foram formadas? A que tipo de singularidade correspondeu esse momento da política educacional do Rio de Janeiro?

Para buscar elucidar o tipo antropológico em que se constituiu singularmente a professora primária pública da década de 1960, durante o governo de Carlos Lacerda, foram realizadas algumas entrevistas com as profissionais das escolas públicas que lecionaram naquele período. Em outras palavras, tratou-se de examinar o tipo específico que caracterizou as profissionais do magistério público, e que correspondia à própria singularidade da instituição naquele momento. Foram escolhidas docentes que, à época, eram regentes de turma, e atuavam em escolas distintas, localizadas em diferentes áreas da cidade.

Assume-se, dessa forma, a compreensão de que a cada instituição que pode legitimamente ser denominada pública - parte total da sociedade que a faz existir - correspondem indivíduos marcados pela mesma singularidade, tanto que

[...] institui-se, a cada vez, um tipo de indivíduo particular, isto é, um tipo antropológico específico: o florentino do século XV não é o parisiense do século $\mathrm{XX}$, não em razão de diferenças triviais, mas de tudo o que ele é, pensa, quer, gosta ou detesta. E, ao mesmo tempo, se estabelece uma verdadeira colméia de papéis sociais, onde cada um é, simultânea e paradoxalmente, auto-suficiente e complementar dos demais: escravo/ livre, homem/ mulher etc. (CASTORIADIS, 2002, p. I49). 


\section{O perfil das professoras}

A educação no ensino primário, na década em foco, era em sua maioria realizada por máo-de-obra feminina - razão pela qual os substantivos referentes aos profissionais da educaçáo públicas encontram-se, ao longo deste artigo, conjugados no feminino. No curso secundário, o percentual praticamente atingia a metade do total dos professores que atuam nessa área. No ensino superior, a preponderância ainda se mantém entre os homens. $\mathrm{Na}$ educação primária, a participação feminina, majoritária, só faz crescer: é possível que isso se deva menos à feminização da docência na educação básica do que ao mesmo fenômeno em outras carreiras que compóem, suplementarmente, o corpo docente desse nível de ensino.

Observe-se a tabela elaborada com base nos censos demográficos do Instituto Brasileiro de Geografia e Estatística (IBGE), sobre a participação feminina no magistério do Brasil.

\section{Percentual de professoras no magistério do Brasil}

\begin{tabular}{c|c|c|c}
\hline & 1960 & 1970 & 1980 \\
\hline Ensino primário & $88.4 \%$ & $93.6 \%$ & $95.4 \%$ \\
\hline Ensino secundário & $47.4 \%$ & $59.5 \%$ & $77.6 \%$ \\
\hline Ensino superior & $18.4 \%$ & $30 \%$ & $42.2 \%$ \\
\hline
\end{tabular}

Fonte: Retrato do Brasil, 1984.

No Estado da Guanabara, no período, era evidente a maioria feminina, como pôde verificar Vasconcellos (I972); 98,8\% do magistério, em I97I, segundo a Secretaria de Estado, compunha-se de mulheres. O perfil dessa profissional é por ela traçado: "O magistério primário é, na Guanabara, uma profissão predominantemente feminina. Os professores são brasileiros 
e cariocas em sua maioria [...]. Mais da metade dos professores é casada." (VASCONCELLOS, 1972, p. 359).

As entrevistas realizadas levam-nos a perceber que a procura pela profissão, além de estar ligada ao desejo pessoal de realizaçáo que a carreira do magistério primário poderia proporcionar, também representava a possibilidade de trabalhar fora de casa, sem abrir mão dos cuidados com o lar e a família:

Eu acho que era uma das poucas oportunidades que as mulheres tinham de se formar, de se profissionalizar. Eu queria muito ser médica, na verdade, mas depois comecei a namorar seriamente, e por isso ficaria muito complicado tornar-me médica. Ser médica era coisa para solteirona, e não para mulher que se casasse. E, a minha opção, então, foi tornar-me professora. (TINDÓ, entrevista).

O que havia de absolutamente singular na carreira de professora da escola elementar, à época, é que a maior parte das especificaçôes do cargo correspondia às exigências normalmente estabelecidas para a mãe-de-família. Outras profissóes, exigindo talvez a mesma dedicação, no entanto, envolviam a construção de habilidades e práticas dificilmente conciliáveis com a vida familiar.

Essa avaliação não resultava apenas da pressão exercida pelo futuro esposo. Algumas professoras levantaram a forte influência dos pais na escolha da profissáo, pois essa opçáo garantia a oportunidade de um bom emprego para as mulheres. Para os pais, o ambiente de trabalho proporcionado pela área da educação básica era extremamente adequado, por se tratar de um espaço eminentemente feminino, em que as relaçōes estabelecidas conservavam, de certa forma, as regras e os valores do lar onde as moças haviam conjecturado o sonho do casamento em um futuro próximo: 
Em toda a minha infância, eu e minhas irmãs só ouvíamos meus pais dizerem que iríamos ser professoras, por ser uma profissão segura, que teríamos independência financeira, e mais: que estaríamos trabalhando num ambiente sadio, pois só lidaríamos com crianças e professoras. (COUTINHO, entrevista).

Existia, no entanto, um sentimento contraditório no interior da família, pois, ao mesmo tempo que incentivavam a profissionalização de suas filhas, estimulando-as a se tornar independentes financeiramente, os pais faziam questão de que escolhessem uma profissão que pudesse preservá-las da convivência masculina. Essas contradições eram assimiladas pelas próprias professoras, e, dessa forma, o magistério passa a ser visto como vocação, como dedicação, como sentimento todo derivado da submissão ao amor, tal como a mulher, à época, demonstrava pelo marido.

Uma das professoras entrevistadas levantou a questão da vocação pelo magistério, apesar de ponderar que isso não significava sacerdócio,

[...] o que me fez ser professora tem a ver com a vocação. Não é esse lance de sacerdócio. Hoje eu não penso dessa forma, mas naquela época eu pensava que magistério era uma vocação tipo padre, médico, aquela coisa retrógrada, antiga, de dedicação total. (ABREU, entrevista).

No entanto, durante esse período, o argumento da dedicação total à profissão não era tão facilmente admitido, posto que a atuação feminina precisava, agora, e cada vez mais, dividir-se entre a casa e a escola. Em outras palavras: a participação da mulher nos postos que lhe eram reservados no mercado de trabalho passava, pela primeira vez, a ser reconhecida como parte integrante do orçamento familiar, e não como um voluntariado do qual não convém, ao homem de boa índole, aproveitar-se. 
De toda forma, durante as entrevistas, ficou claro que as professoras tentaram demonstrar a dedicação ao trabalho escolar como se fosse um dos principais itens para a avaliação do desempenho profissional requisitado. A relação que se estabelece entre a opção pelo magistério e a vocação do sacerdócio tem origem na formaçáo jesuítica do professor, durante o período colonial, fase de formação do povo brasileiro. Entretanto, ela acaba por revelar-se como manifestação dos limites concedidos à participação feminina no espaço público. Percebemos uma nítida imagem subliminar de sacrifício, ligada aos ideais religiosos tão fortemente presentes na ordem dos inacianos, na composiçấo do tipo ideal de mulher que, integrando-se ao mercado de trabalho, na condição de professora, abre caminhos para uma participação mais ampla, e hoje corrente, do feminino na economia.

\section{As professoras e a política lacerdista}

O ingresso das recém-formadas no magistério público dava-se de forma automática, logo após a conclusão do Normal. Uma listagem divulgava a ordem de classificação das alunas que, de acordo com as notas obtidas durante o curso, eram chamadas para escolher a escola em que seriam lotadas. A certeza da contratação representava uma forte razão para a definição da carreira profissional:

Havia uma única listagem de notas das professoras formadas, no Instituto de Educação e na Escola Normal Carmela Dutra, formadas naquele ano; após a divulgação, íamos escolher a escola pela ordem de classificação: quem tinha as melhores notas escolhia primeiro [...](VALLE, entrevista).

A maioria das professoras entrevistadas trabalhou em escolas que adotaram algumas das medidas implementadas pela Secretaria Estadual de 
I O Projeto Piloto foi um plano de educação compensatória voltado para as crianças carentes, que contava com recursos da Fundação Ford.
Educação durante a gestão de Lacerda - como o rodízio de folgas semanais e o regime de três turnos - para ampliar emergencialmente as vagas aos novos alunos. As entrevistadas consideraram as duas experiências relevantes para a expansão de matrículas nas escolas públicas primárias, no Estado da Guanabara. Diferentemente do que se esperava como resposta, a maioria das entrevistadas afirmou que essas medidas não prejudicavam o nível do ensino nos estabelecimentos em que foram desenvolvidas. Apenas uma delas problematizou a escola de três turnos, pois a permanência da criança no estabelecimento de ensino ficava bastante reduzida.

Pode-se supor, pelas afirmações, que as docentes foram tão convencidas pelo discurso governamental que não conseguiram perceber, como evidente, o fato de que a redução de carga horária representava uma perda significativa na qualidade do processo ensino-aprendizagem. Ou será que não? A princípio, era de esperar que o nível do ensino sofresse uma perda com a redução do tempo de permanência das crianças na escola. $\mathrm{O}$ prédio escolar deixava de atender a dois turnos e, nele, passavam a funcionar em três períodos. É claro que, por mais que as professoras reconhecessem a medida como prejudicial aos estudantes, isso não foi suficiente para impedir que os alunos sofressem bastante com a redução da carga horária. Hoje em dia são poucos os que contestariam os benefícios do horário integral para o desenvolvimento das crianças.

Esse era, aliás, um dos pontos programáticos reivindicados pela

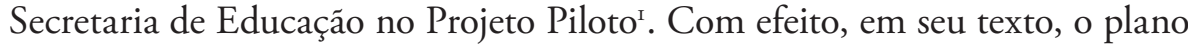
do governo afirmava que:

Os horários de três horas ou quatro horas, em classe, não são suficientes, uma vez que suprimem as atividades indispensáveis à socialização e ao enriquecimento de experiências tais como: recreação livre, música, educação física, teatro infantil, artes, excursôes etc, e dão prioridade à parte acadêmica do currículo, tornando a escola 
não uma agência social, mas sim uma agência de informaçôes, de precária utilidade quanto à aplicação futura da instrução recebida. (PROJETO PILOTO, I966, p. II).

Percebe-se, assim, que o governo, quando se referia a um projeto isolado, em fase experimental, trabalhava com os melhores critérios e condiçôes para o processo de crescimento integral do aluno; entretanto, quando se tratava da realidade concreta - à qual os estudantes eram submetidos diariamente -, a iniciativa oficial demonstrava certa timidez em exercer suas atribuições, e isso justamente onde elas se faziam mais necessárias - numa sociedade urbana que compelia cada vez mais os adultos das classes trabalhadoras ao mercado, tornando-os reféns de um local onde, além de deixar os filhos, pudessem assegurar-se da complementação de sua educação. Isso posto, parece assente que até hoje a educação pública não logra proporcionar as atividades complementares tão necessárias para a socialização e integração da criança à sociedade. Assim, a proposta de educação em horário integral tem-se constituído em imagem explorada por escolas particulares e pouco experimentada, ainda, em âmbito estadual.

Acerca do Projeto Piloto - da experiência pedagógica desenvolvida pela Secretaria de Educação e Cultura do Estado da Guanabara, em parceria com a Fundação Ford - poucas entrevistadas se lembraram. As professoras que comentaram o projeto não o vivenciaram nas escolas, mas falaram pelo que conheciam de seu conteúdo - o projeto, de fato, jamais chegou a se expandir para toda a rede escolar. Fortes são, entretanto, as evidências de que o Projeto Piloto pouco representou nas mudanças efetivas para a educação oficial do Estado da Guanabara. Funcionou, assim, como uma fachada de propostas que serviriam de propaganda para o governo de Lacerda.

Não havia, à época, nas escolas, a figura de uma supervisora ou orientadora pedagógica responsável por encaminhar as questôes pedagógicas. As orientadoras pedagógicas existentes permaneciam nos distritos educacionais. 
As unidades escolares organizavam-se por meio de reunióes periódicas, que podiam ocorrer, inclusive, nos distritos escolares. Nesses encontros, discutiam-se as atividades educativas que seriam desenvolvidas com os alunos:

Eu estou lembrando que foi só a partir do ano de 1969, com a publicação do parecer 252/69 da Secretaria de Educação, que a figura dos supervisores, orientadores e administradores, como especialistas da educação, passou a existir nas escolas públicas. (ABREU, entrevista).

O trabalho pedagógico baseava-se centralmente nos planos de aula, que eram exigidos e cobrados pela direçáo da escola. Por tudo que as professoras afirmaram, percebemos que possuíam muita liberdade profissional em sua rotina diária. Trabalhavam com bastante autonomia em sala de aula, pois náo havia controle pedagógico. Isso demonstra o grau de dedicação e responsabilidade que as professoras mantinham em seu trabalho, uma vez que, apesar de não terem uma supervisora, nos moldes atuais, elas garantiam a qualidade do processo.

Algumas entrevistadas citaram dificuldades vividas quando, por exemplo, recebiam turmas com crianças que apresentavam deficiências físicas, ou de aprendizagem. Verificou-se que essas professoras foram obrigadas a buscar soluçôes e caminhos por conta própria, sem receber qualquer ajuda ou orientação. Pôde-se constatar, entấo, que as docentes necessitavam lutar por conta própria por um auxílio técnico e especializado para algumas demandas constantes na vida das escolas. Uma das entrevistadas cita um caso dessa espécie, afirmando quanto foi difícil encontrar, sozinha, possíveis encaminhamentos para a situação que precisou enfrentar:

Eu, por exemplo, tive problemas porque me transferi para uma escola onde trabalhei com uma turma de alunos que apresenta- 
vam deficiências, com os quais eu nunca havia trabalhado, quer dizer, eu tive que procurar leituras, procurar informaçôes, porque propriamente da escola não tive orientação. (MACHADO, entrevista).

A principal preocupação governamental, à época, era expandir a rede física, o que significava a entrada de crianças portadoras dos mais variados tipos de problemas, e não a garantia de pleno atendimento dos alunos que possuíam necessidades específicas. Nota-se, também nessa questão, a contradição entre o que a Secretaria de Educação propunha em seus projetos, como o próprio Projeto Piloto, e o que, na realidade, era implementado nas escolas oficiais da Guanabara. No texto do referido plano, estava expressa a preocupação com essas crianças, como fica claro na leitura do texto:

As crianças provenientes de áreas menos favorecidas chegam à escola totalmente despreparadas para corresponder às expectativas da estrutura e da organização escolares. Para as deficiências que apresentam, tais como: experiências reduzidas, vocabulário pobre, problemas do desenvolvimento sensorial e da afetividade, valores e crenças diferentes dos padróes da classe média e média alta, não encontram na escola o atendimento adequado. (PROJETO PILOTO, I966, p. 9).

Todas elas têm boas recordaçóes de suas escolas durante esse período. São capazes de lembrar de fatos bem pitorescos, inclusive do nome de suas diretoras: algumas muito rígidas em relação aos horários, outras que estabeleciam uniformes para as professoras regentes.

Destacam que o bom funcionamento das escolas dependia fundamentalmente da atuação das diretoras, visto que, como se afirmou, não havia uma equipe pedagógica como as existentes, atualmente, nas escolas. Isso demons- 
tra que a Secretaria de Educação atuava por meio das direções das escolas que, nesse processo, representavam o canal de comunicaçáo entre governo e as regentes de turma. A comparação com a atualidade mostra que a imagem dos coordenadores regionais sobrepóe-se à das diretoras da época focalizada, em cujas mãos se concentrava grande parte do poder. $\mathrm{O}$ respeito que demonstraram por suas diretoras chamou bastante a atenção, devido à extrema autoridade e rigor com que elas lidavam com alunos e funcionários em geral:

[...] como eu disse, a minha diretora era muito severa. D. Maria do Carmo Castanheira de Almeida não era brinquedo, não. Ela abria e fechava a escola. E ninguém tinha a chave da escola, a não ser ela, a subdiretora e a secretária da escola. [...] Então, D. Maria do Carmo era essa pessoa muito presente. (VALLE, entrevista).

O ambiente nas escolas foi descrito pelas professoras entrevistadas como bastante amigável, onde a cordialidade e a generosidade prevaleciam. Havia troca de experiências, e percebe-se que o grande objetivo era sempre o melhor desempenho no trabalho, de forma que garantisse uma educação pública de bom nível. A preocupação estava constantemente ligada à aprendizagem dos alunos. Havia muita dedicação dessas moças, que ocupavam boa parte de seus horários com a preparação das aulas e os momentos de especialização.

As professoras eram profissionais bastante preocupadas com a educação de seus alunos. Faziam vários cursos de aperfeiçoamento desenvolvidos pela Secretaria de Educação, alguns de curta duração, outros que levavam até um ano, realizados nas dependências das escolas normais. Esses aprimoramentos não implicavam qualquer reajuste ou aumento salarial: as professoras participavam desses cursos, porque os consideravam essenciais para sua formação profissional. Citaram, como exemplo da variedade e amplitude de temas, cursos como educação alimentar, literatura infantil e ativida- 
des em bibliotecas e auditório e de relaçóes humanas. A preocupação com o que hoje chamamos de formação continuada já estava presente no cotidiano do magistério da época.

Durante todo esse período tínhamos cursos de aperfeiçoamento nas várias áreas da Educação, que eram realizados, na maioria das vezes, no I.E. Esses cursos davam conhecimento e aprimoramento ao nosso ofício, o que serviu de base para que o estado se tornasse o modelo de ensino do país. (COUTINHO, entrevista).

A relação com os alunos foi descrita pela maioria das professoras como muito tranqüila. Existia autoridade e firmeza, mas entremeadas pelo carinho. Suas atitudes eram bem maternais com as crianças, como previsto; ocupavam-se das questôes pedagógicas, sem, no entanto, deixar de cuidar do lado pessoal dos alunos, observando a higiene, os cuidados alimentares, entre outros.

A mesma atenção dada pelos professores aos alunos também ocorria no contato com os pais, em encontros periódicos, ao longo do ano, tanto em festas quanto durante atendimentos individuais aos responsáveis, nos quais davam orientaçôes sobre educação dos filhos. Os pais tinham liberdade de circulação nas escolas e participavam de muitas das rotinas pedagógicas, desde excursōes até comemoraçôes de datas cívicas. Isso contribuía para o estreitamento dos laços entre responsáveis e docentes.

O bom ambiente nas escolas e a qualidade incontestável do trabalho que realizavam também possibilitavam a matrícula dos filhos da maioria das professoras, nas instituiçôes em que atuavam como regentes:

[...] era uma escola muito boa, era quase como uma escola padrão, e havia uma coisa que eu falo para as minhas alunas hoje, esta era uma escola para os filhos da gente, não era uma escola para os 
filhos dos outros. Não era uma escola, na qual a gente trabalhava e levava os filhos para a escola particular. Eu, por exemplo, tinha três filhos e os três iam de manhã cedinho comigo. (TINDÓ, entrevista).

Esse depoimento é bastante relevante, pois demonstra a confiança que as professoras depositavam no trabalho que desenvolviam com toda a equipe escolar; em razão disso, a escola pública era valorizada pela sociedade que se sentia segura, pois o corpo docente mantinha seus filhos, sobrinhos e amigos estudando na instituição. Essa situação também colaborava para o cotidiano da mãe-professora, que saía para o trabalho e voltava com os filhos a tiracolo; estes estavam sempre juntos, o que facilitava o convívio familiar, sobretudo com filhos e maridos.

\section{$4 \quad$ A memória de Lacerda}

A construção de escolas foi uma das marcas do governo Lacerda. Ele teve a preocupação de forjar um projeto arquitetônico próprio que identificasse sua gestão, mas que não foi considerado tão bom quanto os prédios mais antigos, erguidos por governos anteriores, como foi ressaltado no projeto de escolas do período de Mendes de Moraes:

Eram escolas mais amplas, mais arejadas, mais claras. As salas normalmente comportavam quarenta a quarenta e cinco alunos, mas permitiam a presença de até sessenta crianças. Eram áreas arborizadas, com amplos pátios para a recreação das turmas, homenageadas com painéis ou murais de pintores brasileiros - o que não existia na maioria das escolas construídas por Carlos Lacerda. (COSTA, entrevista). 
As professoras não conseguiram apontar, no período de governo de Carlos Lacerda, grandes modificaçóes no campo pedagógico, propriamente dito. Além do Projeto Piloto, que não foi executado, outras medidas pedagógicas inovadoras náo foram citadas. Lembraram de que as escolas foram equipadas com coleção de livros para os professores, alguns aparelhos de audiovisual, como projetores de slides e retroprojetores, e que os alunos passaram a receber livros didáticos. Os grandes investimentos restringiram-se, realmente, apenas à ampliaçáo das matrículas e da rede escolar. A prática pedagógica não sofria interferências da Secretaria de Educação do Estado. É interessante o depoimento de uma das professoras que ressaltou serem as escolas muito mais abastecidas de materiais didáticos para uso das crianças, durante o governo de Mendes de Moraes, prefeito do Distrito Federal, do que na gestão Lacerda.

Outro fato rememorado como marcante por todas as professoras entrevistadas refere-se à questão salarial. Elas expressaram a satisfação do professorado da época com a valorização profissional conquistada durante a administração do Lacerda:

Eu considero que o governo Lacerda foi a época em que os professores primários ganharam melhor. Não digo que os professores ganhavam bem, porque nunca se ganhou tâo bem assim, mas tinha-se uma vida digna, que o salário de professor dava para viver, isso dava. (ABREU, entrevista).

Muitas se lembram da organização do plano de carreira, em níveis por tempo de serviço, implantada em seu governo. $O$ plano estruturava-se em diferentes níveis - chamados EPs - que refletiam o tempo de serviço; a mudança de nível ocorria a cada três anos de trabalho. O salário do EP I, que era o nível inicial, correspondia, aproximadamente, a três salários mínimos: 
Por força da Lei 280/ 62 (Guanabara. Estado, 1962) os professores do então denominado curso primário e os técnicos passaram a constituir um quadro destacado do funcionalismo, com efeitos salariais a partir de setembro de 1963. Por este plano de salários, os professores primários tinham, a cada três anos, reajuste de ı०\% sobre o vencimento anterior, sendo o piso salarial de 2,6 saláriosmínimos. (VALLE, 2003, p. I34).

Além disso, o salário, em dinheiro, era entregue às professoras por um funcionário público que percorria as escolas. $\mathrm{O}$ pagamento só passou a ser realizado em conta corrente após a criação do Banco do Estado da Guanabara, o que aconteceu durante a gestáo Lacerda. Por isso, as professoras demonstraram tanta consideração pelo governador - ele foi o responsável por organizar a situação dos cargos e salários do magistério público do antigo estado, que "[...] perdurou, mesmo após a fusão do Estado da Guanabara com o antigo Estado do Rio de Janeiro, em 1975 por um longo tempo [...]", como afirma Valle (2003, p. I34).

Para se ter uma idéia de valores, podemos usar como exemplo a comparação ainda corrente entre os professores - atualmente aposentados - de que os salários do magistério correspondiam aos valores dos soldos dos militares de carreira. Fala-se que o salário do professor primário, já por volta dos quinze anos de carreira, seria equivalente ao de um capitáo, enquanto o do professor de ensino médio se igualaria ao de um coronel, com o mesmo tempo de experiência profissional:

Eu tenho até testemunhos de colegas do segundo grau (Ensino Médio), que confessam terem ingressado neste segmento de ensino por meio de um concurso rigoroso e que, depois de tudo isso, sentiram-se recompensados por um salário muito bom, porque 
recebiam o valor equivalente ao salário de um coronel da Polícia Militar. (MACHADO, entrevista).

A carreira essencialmente feminina sempre favoreceu a redução progressiva dos salários, pois o trabalho das mulheres foi - e ainda é - encarado, em muitas comunidades, como um complemento financeiro para o sustento familiar. A antiga procura das mulheres pelo magistério explica-se, em grande parte, pela reduzida carga horária, outro componente na justificativa para os baixos salários.

Fica evidente, nas entrevistas, que as professoras, com os seus salários, contribuíam, de forma significativa, para o sustento doméstico. Todas se referiram aos gastos pelos quais ficavam responsáveis, na divisão financeira que estabeleciam com seus maridos. $\mathrm{O}$ interessante é que a maioria afirmou que os cônjuges arcavam com as tarifas como luz, gás e telefone, além das despesas alimentares, enquanto elas usavam seus recursos para cobrir seus gastos e o das crianças - como roupas, materiais escolares e todos os extras. Essa prática demonstra que, apesar de fundamental para as famílias, o uso do salário das professoras primárias, na divisão familiar, tendia a refletir a esperada superioridade masculina, que mantinha a responsabilidade pelo sustento essencial de sua família.

Para as professoras primárias entrevistadas, o mito que envolve a figura do governador Carlos Lacerda está diretamente relacionado ao reconhecimento do magistério primário, pela valorização financeira e de todo o investimento realizado no campo da educação. As grandes obras de infra-estrutura, como a construção da Adutora do Guandu (abastecimento de água) e a erradicação de favelas da zona sul da cidade, também foram lembradas por uma docente:

Eu devo reconhecer que, na época, eu não era lacerdista. Eu não tinha muitas afinidades com o Lacerda, mas agora olho para trás e não posso deixar de ver que se não fosse o Lacerda, talvez hoje 
o Rio estivesse vivendo uma situação bastante crítica, caso ele não fizesse todas as obras que fez na cidade. Hoje tenho que concordar que ele foi um bom governante. (TINDÓ, entrevista).

$\mathrm{Na}$ maioria das entrevistas, ficaram explícitas as declaraçóes de profunda admiração política pela imagem do governante. Em outras, percebemos restriçóes à ideologia assumida por Lacerda, pois afirmaram que vinham de famílias tradicionalmente muito próximas, no campo ideológico, de Getúlio Vargas - como podemos constatar por essa entrevistada, que diz: "Meu pai era getulista, eu tinha uma formação nacionalista, eu acho que até o Lacerda também era; todo mundo era nacionalista naquela época, mas eu não gostava dele." (TINDÓ, entrevista). Ela deixou claro que, politicamente, não gostava do governador da Guanabara, mas admitiu o apoio dado por ele à educação.

Todas as professoras entrevistadas concordaram que essa "[...] foi uma época áurea na educação [...]” (ABREU, entrevista) do Rio de Janeiro. Consideraram o governo de Carlos Lacerda a melhor administração que esse setor já vivenciou. E citam tanto as medidas tomadas para ampliação do número de crianças matriculadas quanto a valorização salarial como responsáveis pelo seu bom governo. Mesmo as professoras assumidamente contrárias à política de Lacerda argumentam que esse foi o melhor governo para a educação pública:

A minha família era muito getulista. Só tinha um tio que era lacerdista doente; portanto, eram brigas homéricas. [...] Então, eu fui criada não gostando do Lacerda, que era o "pestinha". Mas com o passar dos anos, a gente vê como seu governo foi grandioso; ele era, realmente, uma pessoa de temperamento muito difícil, uma pessoa de uma facilidade discursiva que não houve igual. (VALLE, entrevista). 
O respeito que o governador da Guanabara demonstrava pela categoria do magistério primário foi a razão para que as professoras se sentissem muito valorizadas. Ele instituiu, politicamente, a educação como uma das áreas fundamentais para garantir o desenvolvimento do estado que, na condição de uma unidade da federaçáo recém-criada, coube a ele a responsabilidade de estruturar.

\section{Consideraçóes finais}

Na prática, Lacerda reconheceu, nas professoras da rede oficial, potencial muito grande de sustentação para seu mandato e ambiçóes futuras. Além disso, compreendeu que priorizar a educação não apenas lhe garantia apoio político dos que diretamente se encontravam envolvidos, mas também significava receber o apoio das famílias dos profissionais e dos pais e responsáveis dos alunos matriculados na rede pública de ensino.

$\mathrm{Na}$ verdade, o que podemos entender, partindo das afirmaçóes das entrevistadas, é que o governo de Carlos Lacerda ficou marcado como uma excelente administração, porque nem os governos subseqüentes obtiveram o mesmo desempenho, nem o investimento na educação foi táo significativo. Uma das professoras, durante a entrevista, expressou-se assim:

Considero Lacerda o melhor governo que o Rio de Janeiro já teve, pelas melhorias, de um modo geral, que ele implantou na cidade [...]. Eu me lembro de que ele foi muito perseguido, e que as pessoas, por ocasiáo de sua eleiçấo, diziam que ele não ia fazer absolutamente nada. (MACHADO, entrevista).

As professoras primárias do período que corresponde à administração de Carlos Lacerda na Guanabara demonstravam estar passando por uma fase 
de transição, em que já era possível perceber, no magistério público, os ideais próprios do feminismo e a valorização do trabalho feminino. Esse fato fica evidente no momento em que as entrevistadas afirmam que a importância da gestáo de Lacerda para a educação foi a concessáo do plano salarial. Ao mesmo tempo, as professoras afirmaram, em várias passagens das entrevistas, a preocupação com seus alunos, a dedicação ao trabalho nas escolas e o envolvimento com o magistério, o que as aproximaria da imagem do 'sacerdócio'.

A professora da década de 1960 era uma mulher que estava conquistando sua independência profissional, mas mantendo o espaço de esposa e mãe, da mesma forma que resguardava, no ambiente de trabalho, o espírito maternal.

O tipo antropológico da professora primária em questão, segundo a conceituação de Castoriadis, constitui-se num modelo particular, com características próprias que garantem sua singularidade, em comparação com outras professoras primárias. As professoras analisadas compóem uma identidade bastante distinta das docentes de hoje.

As professoras primárias que atuavam, durante a gestão de Carlos Lacerda, nas escolas públicas estaduais da Guanabara demonstraram competência profissional e sólido conhecimento pedagógico, adquirido no curso normal e fortalecido ao longo da carreira por meio dos cursos que freqüentavam. A formação nas escolas normais tradicionais era bastante rigorosa, até porque a conclusão do curso garantia o ingresso imediato no magistério público estadual. Estavam orgulhosas do papel social que exerciam como responsáveis por permitir a integração de seus alunos na sociedade. $\mathrm{Na}$ época, a formação intelectual era vista como importante fator de ascensão social para os cidadãos.

A dedicação das docentes ao trabalho foi um dado presente em todas as entrevistas realizadas. Uma das professoras admitiu, inclusive, que, na época em que se encontrava ainda solteira, mudou-se de bairro em companhia dos padrinhos, com o objetivo de permanecer mais próxima do local de trabalho, localizado na zona rural do Estado da Guanabara. Dessa forma, poderia de- 
dicar-se melhor às atividades docentes, organizando os materiais didáticos, elaborando os planejamentos de aula, o que significava a busca por qualidade no ensino público.

\section{Entrevistadas}

Prof. ${ }^{a}$ Bertha de Borja Reis do Valle

Prof. a Maria Luiza Tindó Maximiano da Silva

Prof. a Marlene Adelayde Cabral Coutinho

Prof. ${ }^{a}$ Marly Abreu

Prof. ${ }^{a}$ Mitsi Dias Costa

Prof. ${ }^{a}$ Vilma Machado

\section{Elementary teachers of the Guanabara State AT LACERDA'S TIME: THE CONSTRUCTION OF THEIR ANTHROPOLOGICAL TYPE}

This work intends to comprehend the elementary public education of the old Guanabara State. For this, the text basis on the Cornelius Castoriadis' anthropological type theory. This political period corresponds to Carlos Lacerda's government that deeply marked the teachers of this moment.

KeY wORDs: Anthropological type. Education. Elementary teacher. Guanabara.

\section{Referências}

CASTORIADIS, C. As encruzilhadas do labirinto: a ascensão da insignificância. São Paulo: Paz e Terra, 2002. 
GOVERNO DO ESTADO DA GUANABARA. Projeto piloto: uma experiência em Educação - I962/1965. Rio de Janeiro: Vozes, I966.

RETRATO DO BRASIL, v. 3, n. 6, 1984 .

VALLE, B de B. R. Formulação dos planos de cargos e salários e estatutos do magistério: a nova legislaçấo In: SOUZA, Donaldo B.; FARIA, Lia Ciomar (Org.). Desafios da educação municipal. Rio de Janeiro: DP\&A, 2003.

VASCONCELLOS, Hedy S. R. O professor primário da Guanabara - evasão e permanência. Rio de Janeiro. Dissertação. (Mestrado em Educação)- Pontifícia Universidade Católica do Rio de Janeiro, Rio de Janeiro, 1972.

Recebido em 6 jun. 2007 / aprovado em 24 jun. 2007.

\section{Para referenciar este texto}

COUTINHO, M. A. da G. C. As professoras primárias da Guanabara de Lacerda: a construção do tipo antropológico. EccoS, São Paulo, v. 9, n. I, p. I36-I56, jan./jun. 2007. 